\title{
A DEFINITION OF VISUAL INTERPRETATION CRITERIAS TO MAPPING LAND-USE AND LAND-COVER IN THE BRAZILIAN BIOMES
}

\author{
E.B. Silva ${ }^{1}$, S.H.M. Nogueira ${ }^{1}$, A.P.S.Matos ${ }^{1}$, L.L. Parente ${ }^{1}$, L.G. Ferreira ${ }^{1}$, L. Teixeira ${ }^{1}$, L.S. Almeida ${ }^{1}$ \\ ${ }^{1}$ Image Processing and Geoprocessing Laboratory (LAPIG) - UFG, Campus Samambaia, Goiânia - GO, Brazil (elainesilvaufg, \\ annapaulamatos1, serque, leal.parente, lapig.ufg, lanamarast, lythielle)@ufg.br
}

KEY WORDS: image interpretation, visual inspection, landsat, amazon, cerrado, land-use and land-cover

\begin{abstract}
:
The present work aims to establish of Visual Interpretation Criterias of the land-use and land-cover (LULC) classes of the Brazilian biomes. The process relies on the efforts of experts from each biome, Ph.D. and Master's students, and undergraduate students in research. Due to the particularities, the criterias were elaborated individually for each biome. The classes correspond to MapBiomas collection 04 legend. In each LULC class, the user has the following information: class definition, patterns (e.g., color, texture, roughness), and historical Landsat images (RGB 564) from the dry and rainy periods, as well as high-resolution images and field photos of the class. These visual interpretation criterias was used to generate data of samples for MapBiomas mapping validation. With the help of Visual Interpretation Criterias, experienced and inexperienced interpreters were able to produce high-quality sample data without visual inspection. This initiative, a pioneer in Brazil, is a tool to support future interpretations of Brazilian biomes. The results can be found on Lapig website.
\end{abstract}

\section{Introduction}

Territorial management has demanded, at different scales, rapid responses to decision making. Specifically for the regional scale, Remote Sensing is the main subsidy for mapping and monitoring the land-use and land-cover (LULC) changes. With the increasing availability of data, different methodologies have been tested with the purpose of reducing time and costs (Khatami, 2016; Pal, 2005; Friedl, 1997). To meet this demand for new products, remote sensing has been increasingly using different computational techniques, as cloud computing and automatic classification approaches (Townshend et al., 2013). In this context, there is a need of a robust sample design for the acquisition of consistent training and calibration samples to feed different supervised classification algorithms.

In order to achieve a high quality mappings, it is necessary to use instruments that help and guarantee quality and speed in the visual interpretation of samples using satellite images. This process assumes that the interpreter must understand the landscape representation, where the spectral behavior, the color composition, the tone, texture and shape patterns should offer subsidies for a good classification (Nogueira et al., 2019). However, the subjectivity associated with this process, both by the interpreter and the adopted criteria, still represents an important challenge.

Based on the above considerations, the present work aims to define a visual interpretation criterias for all the Brazilian biomes, considering their specificities, as vegetation type and predominant land use. Our definition was used to validate the annual maps of LULC produced by the Mapbiomas for the entire Brazil (MapBiomas,2019), and is publicly available at https://www.lapig.iesa.ufg.br/chave/

\section{Materials and methods}

Landsat's image interpretation work covered the entire Brazilian territory (Figure 1).
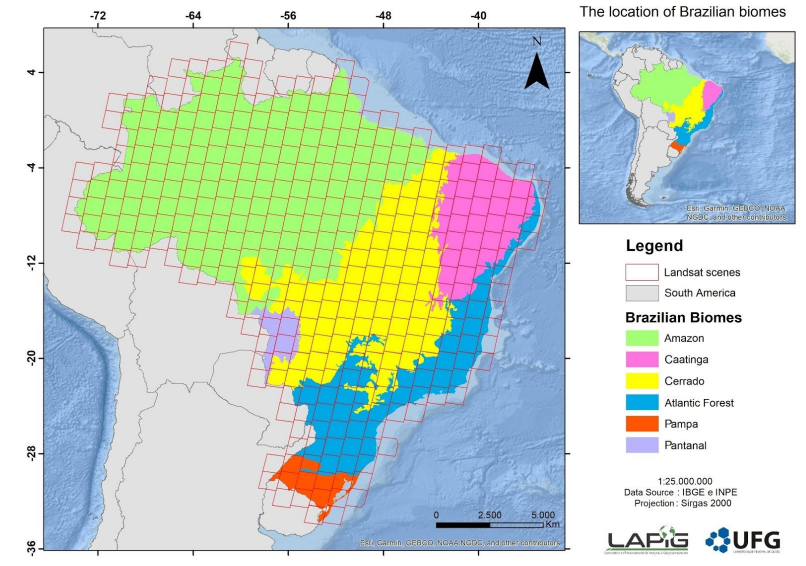

Figure 1. Image Chart of the location of Brazilian biomes.

The LULC classes adopted in this inspection process were elaborated from the legend used in the collection 4 of the MapBiomas (Mapbiomas, 2019), namely: Forest; Non-Forest Natural Formation; Farming; Non-vegetated area and Water Bodies. Altogether, Rocky Outcrops, Salt Flat, Aquaculture, Non-Forest Natural Wetlands, Perennial Crops, Annual Crops, Semi-Perennial Crops (Sugarcane), Grassland Formation, Forest Formation, Savannah Formation, Urban Infrastructure, Mangrove, Mining, Not Observed, Other Non-Forest Formations, Other Non-Vegetated Areas, Cultivated Pasture, Beaches and Dunes, River, Lake and Ocean, Planted Forest.

Regarding the particularities of each class along with the territorial extension of Brazil, individual keys were constructed for each of the six Brazilian biomes. This distinction was necessary once a class, even being present in more than one biome, may have distinct characteristics depending on the particularities of each environment. For instance, there is the savannah formation that can be found in most Brazilian biomes. 
The elaboration of each key was carried out jointly by a group of interpreters (i.e. undergraduate students in research, students in Master's and $\mathrm{PhD}$ courses from the Federal University of Goiás (UFG) and a multi-institutional team consisting of experts in each biome (researchers from NGOs), private companies and higher education institutions. The construction of these keys was carried out through 3 steps. In the first, the interpreters obtained socioeconomic and environmental knowledge of the biome. Afterward, each analyst received a set of points (Landsat pixels) to be discussed with this group of interpreters. The inspections were made through the open-source tool Temporal Visual Inspection - TVI (Nogueira et al., 2017) developed by the Image Processing and Geoprocessing Laboratory (LAPIG) of the Federal University of Goiás (UFG). It is emphasized the relevance of this tool in terms of agility and the provision of subsidies that facilitate and streamline the process of interpreting a historical series of images. In addition to viewing historical images, the tool also makes it possible to visualize the inspected point in a high-resolution image (by Google Earth), for the 2000-2018 period, of a graph of the NDVI values corresponding to the MODIS sensor product MOD13Q1 (Figure 2)
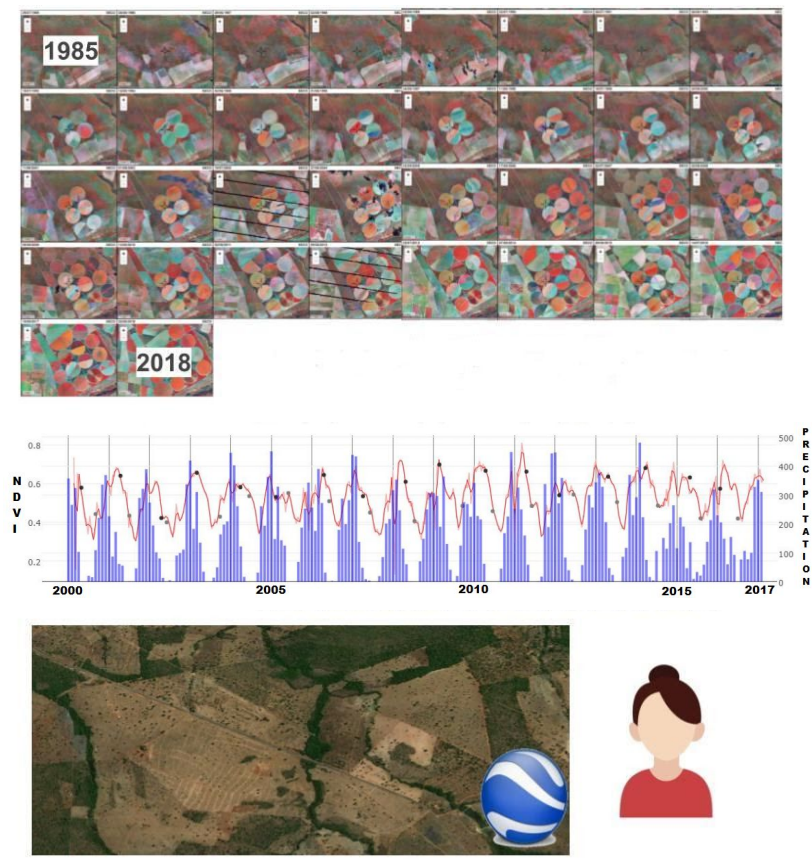

Figure 2. Example of using TVI - Temporal Visual Inspection

In the second stage, with the presence of a biome specialist, analysts went through another phase of biome understanding, considering the classes and analysis of the inspected pixels/points. At the end of the process, experts and analysts jointly elaborate the key to interpreting the biome. This methodology was repeated for all biomes.

\section{The Visual Interpretation criteria}

The key can be accessed through the link https://www.lapig.iesa.ufg.br/chave/ and presents three levels of choice (Figure 3). At the first level, the user chooses the biome. At the second level, the choice of the class to be analyzed is made. At the third level are the description, the criteria that must be observed when inspecting the class and the items related to color, texture, and shape. Landsat images referring to the dry and rainy periods, a high-resolution auxiliary image (by Google Earth), and a field-class photo are also displayed.

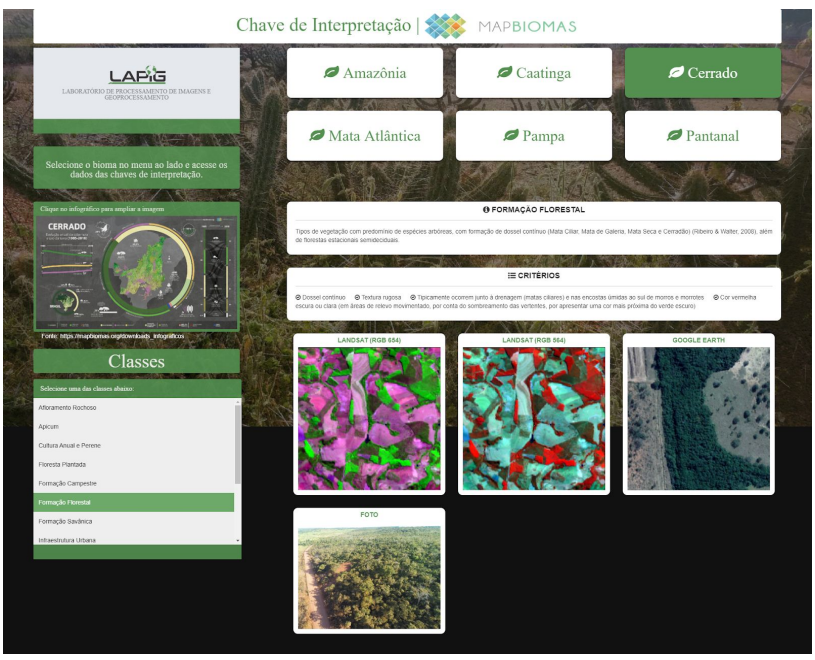

Figure 3. Interpretation key of Brazilian biomes. $<$ https://www.lapig.iesa.ufg.br/chave/>

Even with the support of an interpretation key for each Brazilian biome, several difficulties were observed by the interpreters. Below, we present the main problems in the analysis of the biome classes; these are important conclusions that the interpreter should be aware of when making future inspections.

\subsection{Atlantic Forest}

Landscape variability and their fragmentation were the main struggles encountered in the Atlantic Forest. Confusion swells between perennial cultures and forest formations, as well as very similar patterns between ancient pine and eucalyptus (forestry) plantations and Forest Formations (Figures 4a and 4b). Another difficulty encountered was the spectral similarity between Grassland Formation and Cultivated Pasture, located mainly in altitude fields present in the south of the biome (Figures $4 \mathrm{c}$ and $4 \mathrm{~d}$ ).
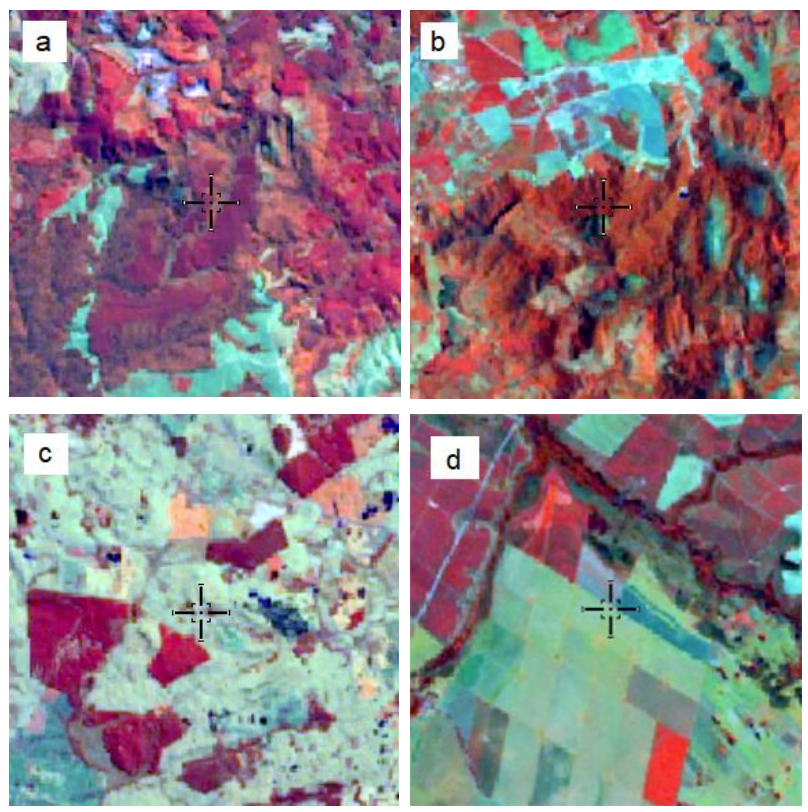

Figure 4a. Planted forest; Figure 4b. forest formation; Figure 4c. Grassland formation; Figure 4d. Cultivated Pasture. 


\subsection{Cerrado}

The main difficulties were encountered in the differentiation between Grassland Formation and Savannah Formation, thereby outlining the transition areas between these two formations (Figure 5a and 5b). Confusions were also observed between Grassland Formation and Natural Pasture, and Annual Crop and Semi-Perennial Crop, due to the similarity of patterns observed in the planting period and the appearance in the dry period (Figures 5c and 5d).
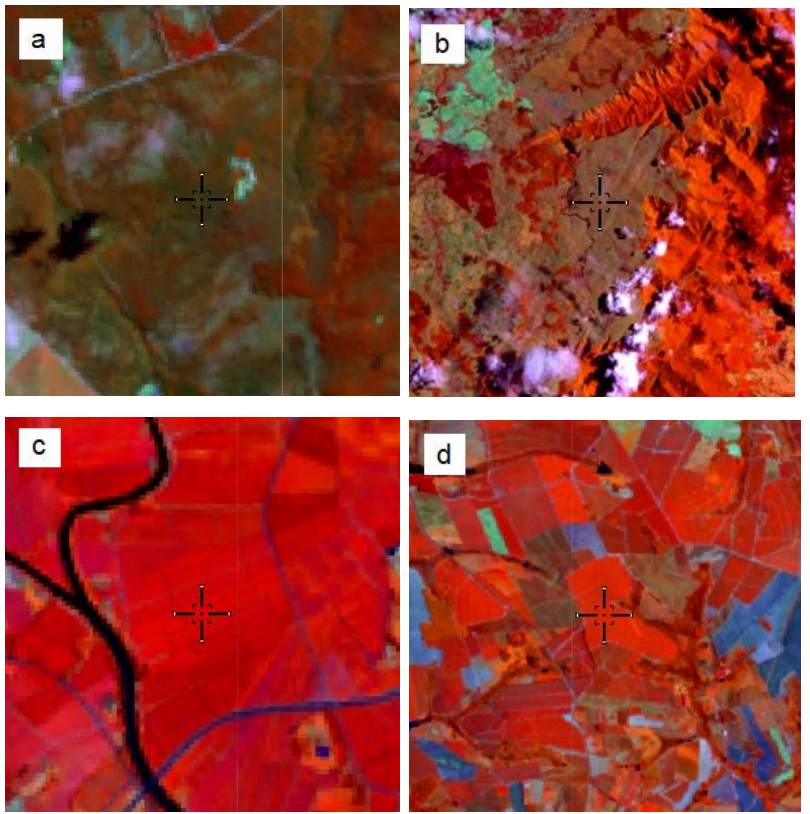

Figure 5a. Savanna Formation; Figure 5b. Grassland Formation; Figure 5c. Annual Crop; Figure 5d. Semi-Perennial Crop.

\subsection{Pampa}

The greatest obstacles found were to distinguish Grassland formation and Annual Culture (Figures 6a and 6b). The management between these two classes occurs intensely, a fact that makes it challenging to inspect these targets, which is only noticeable the difference with the rainy season images. In fragmented areas, especially located in undulating reliefs, confusion between the inspected classes may be justified by the limited spatial resolution of sensors embedded in Landsat series satellites. It is also worth mentioning the hardship in differentiating between wetlands and humid grassland. To identify them, it was necessary to carefully observe the temporal and spatial contexts, considering that the latter are present near the coast.
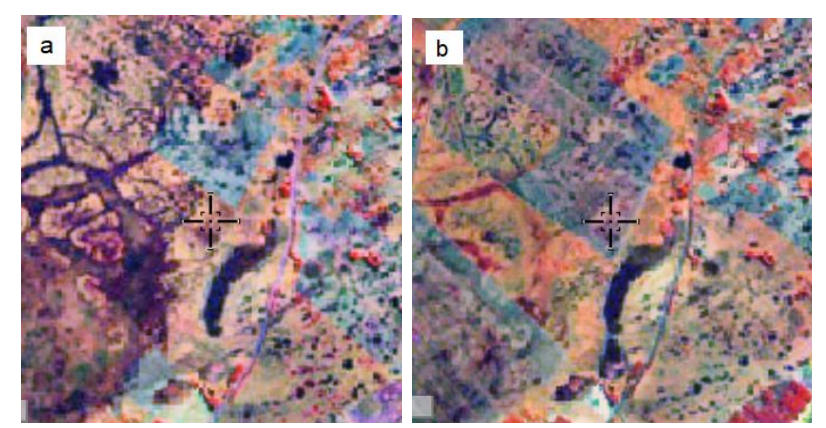
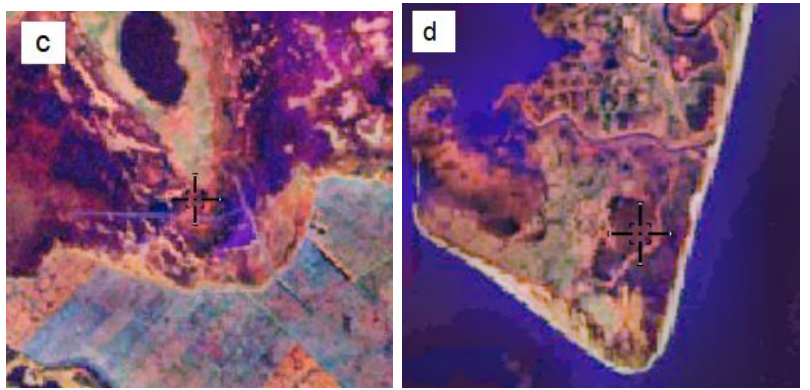

Figure 6a. Natural pasture or grassland formation; Figure $6 \mathrm{~b}$. annual culture; Figure 6c. humid grassland; Figure 6d. wetland.

\subsection{Pantanal}

Due to the seasonality of the Pantanal, the main issue raised was the distinction between Wetland and Grassland Formation (Figures 7a and 7b). Another complication observed in distinguishing between Forest and Savannah Formation is justified by the fact that Savannah Formations in the Pantanal biome have spectral characteristics that approximate the Forest Formation (Figures $7 \mathrm{c}$ and $7 \mathrm{~d}$ ).
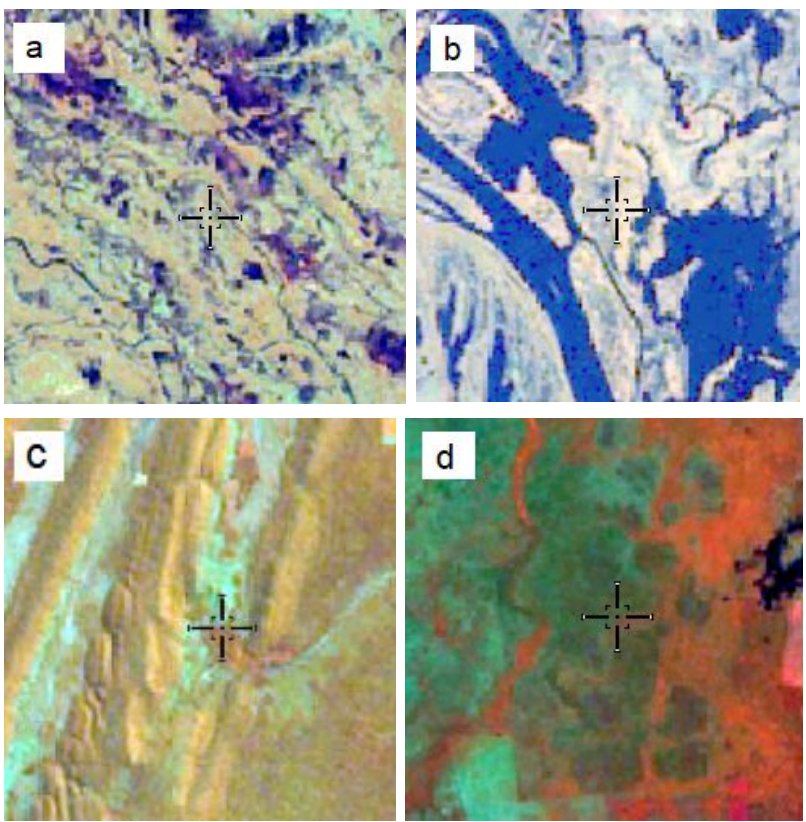

Figure 7a. Grassland Formation; Figure 7b. Wetland; Figure 7c. Forest Formation; Figure 7d. Savannah Formation.

\subsection{Caatinga}

Pastures and native vegetation present similar spectral responses, making the contrast strenuous due to low concentration or absence of grasses (Figures $8 \mathrm{a}$ and $8 \mathrm{~b}$ ). It is also noteworthy the high fragmentation of the landscape in this biome. Caatinga properties are generally small, which causes mixing and spectral blurring of the targets. Due to the greater spacing between trees and a similar spectral response to exposed soil, another class of difficult inspection was Perennial Crops (Figure 8c). Finally, the high incidence of clouds has reduced the availability of images for both dry and rainy periods. 

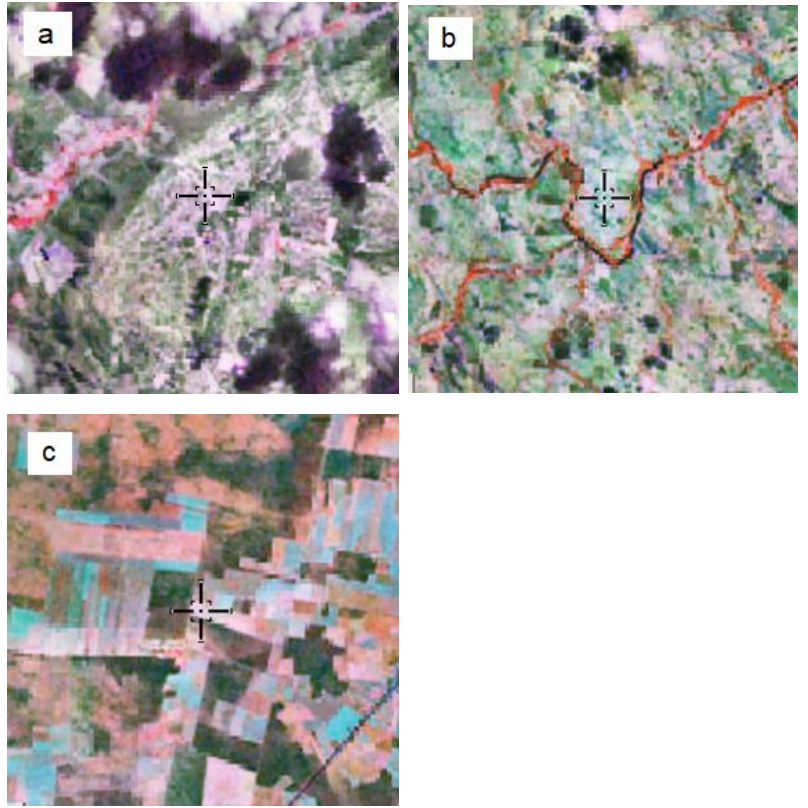

Figure 8a. Natural Pasture, grassland formation or presence of clouds; Figure 8b. Cultivated pasture; Figure 8c. Perennial Crops

\subsection{Amazon}

The homogeneity of the landscape in this biome has made it easier to be interpreted. However, regions with other non-forest natural formations were confounded with natural pastures and cultivated areas in the northeast of this biome. Also to be highlighted is the limitation of images due to the high incidence of clouds (Figures 9a and $b$ ).
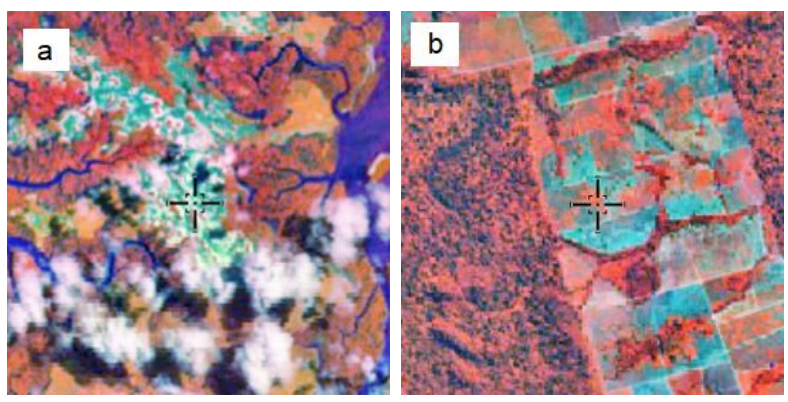

Figure 9a. other non-forest natural formation and presence of clouds; Figure 9b. Cultivated pasture.

\section{Conclusions}

Amid the demand for rapid processing to meet various spatial and temporal scales, the automation process still lacks good visual inspection data. This initiative to develop an interpretation key, based on specific visual criteria for each biome, aimed to contribute to the generation of reliable sample data for the entire Brazilian territory. It is important pointing out that $40 \%$ of the scientific initiation interpreters, at the beginning of the activities, did not know Remote Sensing, which has made the interpretation key an essential tool for the success of the activities.

This tool also played an essential role in distinguishing difficult classes. With well-established criteria, we were able to generate a large dataset to feed algorithms for automatic classification and helps the validation of Brazilian maps of MapBiomas initiative.

\section{ACKNOWLedGements}

This work, located within the framework of the MapBiomas initiative (http://mapbiomas.org), had the support of 15 undergraduate students in research.

\section{REFERENCES}

Khatami, R.; G.Mountrakis;Stehman,S.V. Ameta-analysisof remote sensing research on supervised pixel-based land-cover image classification processes: General guidelines for practitioners and future research. Remote Sensing of Environment,Vol.177,pp. 89-100, 2016 .

MAPBIOMAS. Cobertura e Uso do Solo. Available online: http://mapbiomas.org (accessed on 26 October 2019).

Nogueira, S.H.M.; Faria, A.S; Araújo, A.; Camargos, G.; Matos A. P.; Raine. J.; Razoto, P.P.; Silva, I.H.S.; PARENTE, LL.; FERREIRA, LG. Interpretação visual de pontos em imagens históricas landsat (1985-2017) para a classificação do uso e cobertura do solo nos biomas brasileiros. In XIX Simpósio Brasileiro de Sensoriamento Remoto: Santos, Brasil, 2019.

Nogueira, S.H.M.; PARENTE, LL..; FERREIRA, LG.. Temporal Visual Inspection: Uma ferramenta destinada à inspeção visual de pontos em séries históricas de imagens de sensoriamento remoto. In XXVII Congresso Brasileiro de Cartografia; Instituto Brasileiro de Geografia e Estatística: Rio de Janeiro, Brazil, 2017.

Parente, L.L..; Ferreira, L.G.; Faria, A.S.; Nogueira, S.H.M.; Araújo, F.M.; Teixeira, L.; Hagen, S. Monitoring the brazilian pasturelands: A new mapping approach based on the landsat 8 spectral and temporal domains. International Journal of Applied Earth Observation and Geoinformation, v. 62, p. 135-143, 2017.

Townshend, J.R.; J.G. Masek; C. Huang; E.F. Vermote; F. Gao; S. Channan; J.O. Sexton; M. Feng; R. Narasimhan; D. Kim; K. Song; D. Song.; P. Song; P. Noojipady; N. Tan; M. Hansen; M. Li; R.E. Wolfe, 2012. Global characterization and monitoring of forest cover using Landsat data: opportunities and challenges. International Journal of Digital Earth. Vol. 5, N 5, pp. 373-397. 